\title{
A EDUCAÇÃO E A SOCIEDADE ATUAL FRENTE ÀS NOVAS TECNOLOGIAS
}

\author{
LARA WEILER \\ Iweiler@bol.com.br
}

\begin{abstract}
This paper is about children's education face new technologies. In the beginning of historic times the education and formation of children suffered changes that day by day facilitate more its cognitive development and learning in school context. The children get involved then their wishes of learning and going to school have increased. Currently, it has been discussed and invested in new technologies to education, mainly to children of elementary education that since early have contact with computerization and new technologies. The use of new technologies made possible the change of information trough participation in discussion, lists of e-mail or chats that allow to talk by computer. We can observe development of programs in away education, on- line, through computers occur communication between teacher and student the class not presence form students each time more. The facilities of access webs and advances in telecommunication change the concepts of presence and distance in education developing reasoning, creativity, intelligence and motor coordination. Learning is reorganize the structures of knowledge interacting thought styles, knowing and the know to made that occur trough dialogue process among people. Therefore, the internet has big qualities and varieties but many times occur lack of structure, orientation and instruction to its users. The use of internet in education and its development facilitated interaction of teacher, computer and student being possible to verify and organize better this system clarifying doubts and direction the student to think and learn to learn.
\end{abstract}

\section{INTRODUÇÃO}

A dinâmica social tem evoluído e, a partir dos últimos anos, essa realidade se faz mais veloz, conduzindo a uma nova sociedade: a sociedade do conhecimento. Nessa nova sociedade priorizam-se as necessidades, interesses, estilos e ritmos de aprendizagem de cada indivíduo. Um novo modelo pedagógico que surge com a sociedade da informação e do conhecimento deve ser centrado na aprendizagem mediada pela tecnologia, através dos múltiplos recursos, como por exemplo, os da Internet que são: web, e-mail, fóruns, chats, videoconferência, entre outros. 
A sociedade tem utilizado as novas tecnologias em larga escala em todos os níveis, trazendo modificações profundas nos mais diferentes ramos da ciência. Tais mudanças modificaram intensamente as concepções do desenvolvimento cognitivo do indivíduo. Os estados cognitivos dos seres humanos têm se desenvolvido mantendo uma relação estreita com os avanços da inteligência artificial, sendo comparada, muitas vezes, com um sistema computacional: "a inteligência ou a cognição são resultados de uma rede complexa" (Lévy, 1994, 135).

Ainda, para ressaltar a idéia acima mencionada, Janlert (apud FRAWLEY 2000, p. 214), coloca:

\footnotetext{
Seja como for, se quisermos considerar a linguagem para o pensamento como uma questão computacional, então, uma forma de faze-lo é lê-la como o desenvolvimento e o domínio de um código privado para a escolha entre sistemas equivalentes do ponto de vista informal - exatamente a definição que um cientista da computação dá ao problema da estrutura.
}

O autor faz a mesma comparação ao se referir a forma como ocorre o controle da linguagem para o pensamento e considera tal processo como um sistema computacional. Com isso, até mesmo o processo educacional e de aprendizagem se modifica. Sendo assim, as novas tecnologias aplicadas no contexto educacional vêm proporcionar uma reestruturação na maneira de aprender e ensinar.

\section{MUDANÇAS E REORGANIZAÇÃO}

É essencial compreender que a simples adoção de recursos tecnológicos, em atividades pedagógicas, não significa a ocorrência de mudanças ou rupturas com as formas convencionais de ensino e aprendizagem. Esclarecendo equívocos oriundos da promessa de modernização das organizações através da adoção das tecnologias de informação e comunicação, Morais afirma que (2000, p. 132):

Não é suficiente adquirir televisão, videocassetes, computadores, sem que haja uma mudança básica na postura do educador. É preciso mais. A comunicação precisa ser instaurada, desejada, conquistada. É necessário entender o educando como ser histórico, ativo e como tal, a atenção não pode centrar-se apenas no instrumento e na técnica [...]. Deve-se, necessariamente considerar a influência das imagens no cotidiano do educando. E mais, deve-se observar o reflexo dessa influência de compreender a realidade na sua forma perceptiva, sensorial e cognitiva [...] multidimensional.

Lidar com a pluralidade é o grande desafio que se apresenta ao homem do futuro. As novas tecnologias da informação e da comunicação, se bem utilizadas, poderão auxiliar o cidadão deste novo milênio a encontrar os caminhos das novas relações interpessoais e novas relações com o conhecimento que a denominada era 
da informação exige de todos. Os avanços tecnológicos estão presentes em toda a parte. Não há como ficar indiferente a isto, pois está presente no dia-a-dia de todos os indivíduos, trazendo novas informações como uma nova forma de comunicação. Com isso destaca-se a importância de introduzir tais avanços no cotidiano educacional aque a criança pertence. Ou seja, o ambiente tem papel fundamental no desenvolvimento intelectual da criança, como exemplifica a teoria sociocultural de Vygotsky (STERNBERG, 2000).

Com a chegada das redes de computadores e da mídia no contexto educacional, os estudantes participam e entram em contato com os melhores pesquisadores das diversas áreas do conhecimento de seu interesse específico. Desta maneira, o professor não mais será apenas um propagador do conhecimento, como ocorria anteriormente, mas um incentivador da aprendizagem, gerenciando-a e propiciando uma troca no campo do saber. A utilização das novas tecnologias tornou possível à troca de informações através da participação em listas de discussão, do correio eletrônico ou em chat, que permite a conversa pelo computador. Pode-se observar o desenvolvimento de programas no ensino a distância, online, em que, através dos computadores, ocorre a comunicação do professor com o aluno, resultando que as classes virtuais formam cada vez mais alunos no ensino não presencial.

A capacidade de produzir sons, imagens, textos e animações pelo computador, também contribuem na qualidade do ensino, redefinindo o papel da educação. As facilidades de acesso às redes e os avanços nas telecomunicações mudam os conceitos de presença e distância, no ensino, desenvolvendo raciocínios, criatividade e aguçando a inteligência e coordenação. As imagens animadas exercem um fascínio semelhante às do cinema, vídeo e televisão. Os lugares menos atraentes visualmente costumam ser deixados em segundo plano, o que acarreta, às vezes, perda de informações de grande valor (MORAN, 1998). Nesse sentido, aprender é reorganizar as estruturas do conhecimento, interagindo os estilos de pensamento e o saber realizar, que ocorre em um processo dialógico intersubjetivo, subjetivo e também com o universo em que se encontram inseridas e contextualizadas. Assim, a Internet possui dimensões gigantescas e com grandes potencialidades e variedades, ocorrendo muitas vezes uma falta de estrutura, de orientação e de instrução para seus usuários. Assim, seu uso e desenvolvimento na educação promove a interação do professor, computador e aluno, sendo possível verificar e organizar melhor este sistema, esclarecendo dúvidas e direcionando o aluno a pensar e a aprender a aprender.

Dessa forma, tendo a educação como elemento-chave na construção de uma sociedade baseada na informação, no conhecimento e no aprendizado, o governo vem criando diversos projetos e estimulando parcerias que envolvem a informatização do ensino, a capacitação de docentes e a prática do ensino a distância. O MEC criou no dia 9 de abril de 1997, através da Portaria n. 522, o Programa Nacional de Informática na Educação (Prolnfo), com o 
objetivo de introduzir novas tecnologias de informação e comunicação nas escolas públicas de ensino médio e fundamental. O programa vem sendo desenvolvido pela Secretaria de Educação a Distância (SEED), do MEC, em parceria com os governos estaduais e algumas prefeituras (MORAN, 1998). Não se pode continuar produzindo uma educação onde as pessoas sejam incapazes de pensar e de construir seu conhecimento. Na nova escola, o conhecimento é produto de uma constante construção, das interações e de enriquecimentos mútuos de alunos e professores (MORAIS, 2000).

\section{A ERA DIGITAL}

Novas maneiras de pensar e de conviver estão sendo elaboradas no mundo das telecomunicações e da informática. Segundo Lèvy (1993), as relações entre os homens, o trabalho e a própria inteligência dependem, na verdade, da metamorfose incessante de dispositivos informacionais de todos os tipos. Não se pode mais conceber a pesquisa científica sem uma aparelhagem complexa que redistribui as antigas divisões entre experiência e teoria. Com a evolução e uso crescente das redes eletrônicas de informação e comunicação, observa-se o surgimento de novas categorias de conhecimentos, aprendizagens e racionalidades. Lévy (1993) classifica o conhecimento em três formas distintas: oral, escrita e digital. Atualmente, constata-se que as três categorias coexistem, mas torna-se fácil perceber que a modalidade digital cresce e se dissemina vertiginosamente, caracterizando a era digital.

O amplo acesso a informações e conhecimentos e a velocidade crescente das comunicações digitais torna este meio indiscutivelmente um agente potencializador das interações sociais e ao mesmo tempo dinamizador das novas ecologias cognitivas. Segundo Kensky (1998, p. 61):

\footnotetext{
O estilo digital engendra, obrigatoriamente, não apenas o uso dos novos equipamentos para a produção e apreensão do conhecimento, mas também novos comportamentos de aprendizagem, novas racionalidades, novos estímulos perceptivos. Seu rápido alastramento e multiplicação, em novos produtos e em novas áreas, obriga-nos a não mais ignorar sua presença e importância.
}

Nas instituições acadêmicas, observa-se o uso crescente da Internet por professores e alunos, produzindo mudanças e impactos nos modos convencionais de ensino e aprendizagem. É indiscutível que as dinâmicas sociais nos ambientes virtuais são bastante distintas daquelas que ocorrem tradicionalmente nos ambientes reais. Seria oportuno mencionar que é evidente a cisão ou hiato que se constroem comumente pelos atuais atores sociais que interagem nos ambientes reais e virtuais. Em referência a tal aspecto, Palazzo (2000, p. 47) explica: 
É preciso notar que a comunidade virtual não substitui a real ou parte dela. Ao contrário, real e virtual estão amalgamados na evolução da comunidade total e a incorporação do virtual não ocupa o espaço do real, mas sim o amplia. A evolução do espaço virtual deve, portanto projetar-se no real e viceversa, melhorando processos de aprendizado, comunicação, qualidade da pesquisa e contribuindo para a evolução da comunidade como um todo e ao mesmo tempo de cada um dos seus membros individualmente.

Esta categorização do conhecimento e da aprendizagem digital insere processos pedagógicos capazes de mobilizar competências relacionadas à construção individual e coletiva do conhecimento. Com a disseminação do acesso à Internet, prolifera-se a formação de grupos de interesse, ou comunidades virtuais.

\section{O USO DAS NOVAS TECNOLOGIAS AO ENSINO}

$\mathrm{Na}$ sociedade da informação, as novas tecnologias vêm a oferecer a toda a escola um espaço enriquecedor, com os mais variados instrumentos de informação, possibilitando aos mesmos um aprendizado amplo. Segundo Munhoz (2002, p. 49), "as mídias devem ser utilizadas não como meros instrumentos tecnológicos. Elas podem servir como meio de incentivar e despertar o desejo pela pesquisa e participação, tornando o ambiente de aprendizagem colaborativo." A educação voltada às novas tecnologias vem a ser uma educação colaborativa e participativa (MUNHOZ, 2002), pois os ambientes de redes que os alunos utilizam para desenvolverem seus conhecimentos irão fornecer a eles várias informações ao mesmo tempo, fazendo que ocorra uma aprendizagem interativa, autônoma, criativa e uma construção coletiva do conhecimento.

Machado (2004, p. 99), salienta também que:

Não parece haver dúvidas sobre as imensas possibilidades da tecnologia na sala de aula. Os recursos para instrumentar ação do professor, nos diversos níveis de ensino, são cada vez mais numerosos. Os computadores são ótimos para acumular dados, [...]. Os computadores impregnam a comunicação de tal forma que, caprichosamente, hoje, eles são mais imprescindíveis [...]

Evitar a emergência de um mero conhecimento superficial dos dados ou informações adquiridas depende somente do interesse do aluno e do incentivo do professor em fazer com que este vá além, buscando mais informações para sanar suas dúvidas, levá-lo na sala de aula a debater com todos os membros os assuntos, questionar e levar em consideração todas as reflexões, aprofundar-se em posições cientificamente comprovadas sobre os tópicos, pois o saber não é estático, uma vez que está sempre em constante modificação (MUNHOZ, 2002). 
Munhoz (2002, p.39) diz: "a utilização destes recursos deve incentivar os alunos a uma maior participação em projetos trabalhando na construção individual do conhecimento". O professor deve ter em mente que é um orientador, ao invés de um detentor do saber, tem que assumir a postura de que a educação não é um ato neutro e sim, extremamente político (FREIRE, 1982). Assumindo tal atitude, deve, juntamente com seus alunos, definir como estes meios irão ajudá-los a desenvolver o conteúdo proposto, fazendo com que atinjam seus objetivos.

Essa nova forma de educar e, ao mesmo tempo, aprender a lidar com essas situações está presente no dia-a-dia de cada um. O educador tem que constatar que não pode ficar indiferente a esta situação, pois ela está presente em toda a parte e em todas as áreas, podendo contribuir, e muito, para o ensino tanto dentro como fora da sala de aula (MORAES, 2000). Tanto o professor quanto o aluno têm apenas que saber usar as tecnologias, voltando-as para a educação, pois elas não são nem a favor nem contra a educação, mas podem ser direcionadas para tal, trazendo inúmeros benefícios. Ao usufruir das tecnologias na educação, referindo-se a tudo que o homem já inventou até agora, ela não é apenas a informática, e sim todos os elementos físicos como métodos e técnicas usados por todos os seres humanos até hoje, os quais vêm contribuir para um desenvolvimento mais amplo do ser humano em todas as suas potencialidades.

\title{
O PERFIL DO EDUCADOR VOLTADO À EDUCAÇÃO COLABORATIVA
}

Todo o avanço enfrentado ao longo dos anos na sociedade acarretou uma transformação geral, rompendo paradigmas, ou seja, padrões. Estas transformações igualmente trouxeram ao educador mudanças, em que ele passa a ponderar, se preparar e a questionar sobre a própria práxis e sobre o desenvolvimento do seu papel perante a nova sociedade da informação. Nóvoa (apud MUNHOZ, 2002, p. 51), afirma que:

\begin{abstract}
Não gosto de fazer futurologia. Acho esse terreno repleto de armadilhas e banalidades. Paixão pelo futuro freqüentemente significa déficit do presente. Por isso, falo de apenas um aspecto: nesse século, devido à complexidade do fenômeno educativo, à diversidade das crianças que estudam e aos dilemas morais e culturais que seremos chamados a enfrentar, teremos de repensar o horizonte ético da profissão. Acredito que os próximos anos serão marcados pela instabilidade e pela incerteza. A atitude ética não depende só de cada um de nós, mas da possibilidade de uma partilha efetiva com os colegas. Precisamos reconhecer, com humildade, que há muitos dilemas para os quais as respostas do passado já não servem e as do presente ainda não existem. Para mim, ser professor no século XXI é reinventar um sentido para a escola, tanto do ponto de vista ético quanto cultural.
\end{abstract}

O que o escritor e pensador coloca é que o educador deve repensar no seu papel quanto a valores e conceitos como pessoa e profissional, e adotar uma 
medida mais colaborativa, especialmente na prática docente, para que todos juntos possam educar para um futuro mais digno diante da sociedade da informação. O novo educador deve estar aberto às novas descobertas, encarar as novas tecnologias como auxiliares no seu desenvolvimento educacional e, através desses equipamentos que fazem parte do dia-a-dia do seu aluno, chamar a atenção para o uso de tais meios em educação. O educador precisara saber manusear os meios de comunicação, interagir e criar em seus alunos o gosto pela pesquisa com a utilização dos novos recursos. Sob este aspecto, a comunidade virtual fornece tanto ao aluno como ao professor uma aprendizagem colaborativa (MUNHOZ, 2002), pois, ao debater certos temas, eles mesmos aprofundam seus conhecimentos e tentam achar soluções. Deve-se salientar que nestes meios todos podem relacionam determinados problemas com a vida diária de cada um, ter sua opinião considerada, negociar e entrar em acordo. Em suma, os conteúdos que serão desenvolvidos pelo educador-orientador deverão levar em conta a realidade vivida pelo aluno. A educação voltada aos meios tecnológicos visa à apropriação coletiva do conhecimento, proporcionando um saber interativo.

\section{A CRIANÇA FRENTE ÀS NOVAS TECNOLOGIAS}

A criança passou por um grande desenvolvimento cultural ao longo dos séculos, passou a ter grande valor na sociedade atual e sofreu influência, tanto direta quanto indiretamente, dos avanços tecnológicos inventados pelo homem. Ao mesmo tempo, os valores socioculturais da criança se modifica a cada momento. Um exemplo bem claro que se tem é a brincadeira dita tradicional: quase não se vê mais a criança brincando de roda, ciranda, pião, sapata, pula-corda, pé-de-lata, entre outras, pois o universo no qual está inserida atualmente é repleto de novas tendências. Ela está inserida em uma sociedade de conhecimento e informações, onde os meios de comunicação proliferaram (KENSKY, 1998), tendo contato direto com estes meios através da mídia, principalmente pela televisão, internet, e rádio.

Destaca-se, nesse ponto, a importância que o ambiente tem no desenvolvimento intelectual da criança, pois grande parte da aprendizagem ocorre através das interações com o meio social, conforme a teoria do desenvolvimento sócio-histórico de Vygotsky (STERNBERG, 2000). Ou seja, sua teoria tem por base o desenvolvimento do indivíduo como resultado de um processo sócio-histórico, enfatizando o papel da linguagem e da aprendizagem nesse desenvolvimento. Em sua teoria, destacam-se duas idéias principais: a internalização e a zona de desenvolvimento proximal (ZDP). A internalização é a construção do conhecimento; já a ZDP é o diferencial de habilidade entre o nível de capacidade observável, que é a performance de uma criança, e a capacidade latente, que é a aptidão (STERNBERG, 2000). A psicologia de Vygotsky tem papel fundamental na ciência cognitiva. Sua obra não é uma explicação do "externo", mas uma teoria da internalização, ou seja, uma relação entre o "externo" e o "interno". 
Sobre isso, Sternberg (2000, p. 384):

(...) enfatiza o papel do ambiente no desenvolvimento intelectual da criança. Postula que o desenvolvimento procede enormemente de fora para dentro, pela internalização - a absorção do conhecimento proveniente do contexto. Assim, as influencias sociais, em vez de biológicas, são fundamentais na sua teoria.

A "era da informática" trouxe para as crianças muitos instrumentos que podem particularmente atrativos pelo simples fato de produzirem efeitos especiais, serem parecidos com o real, terem formas e cores chamativas e até o poder de introduzi-las em um mundo mágico onde o espectador é ela própria. Por isso, as crianças mostram-se hoje tão fascinadas pelos meios eletrônicos, que são suas novas formas de brincar, de pô-las em contato com uma ampla gama de informações e de contribuir de forma global e integral ao seu desenvolvimento infantil, na medida em que desenvolvem sua criatividade e suas habilidades para desenvolverem-se cognitivamente e socialmente, preparando-se para o futuro.

\section{BIBLIOGRAFIA}

BRASIL. Estatuto da Criança e do Adolescente. Lei n. 8.069, de 13 de julho de 1990. Dispõe sobre o Estatuto da Criança e do Adolescente e dá outras providências. Brasília, 13 de julho de 1990. Conselho Municipal dos Direitos da Criança e do Adolescente. Santa Maria: Pallotti, 2002.

FRAWLEY, William. Vigotsky e a Ciência Cognitiva. Porto Alegre: ARTMED, 2000.

FREIRE, Paulo. A importância do ato de ler. São Paulo: Cortez, 1982.

KENSKY, Vani Moreira. Novas Tecnologias. O redimensionamento do espaço e do tempo e os impactos no trabalho docente. In: Revista Brasileira de Educação no 7. Associação Nacional de Pós-Graduação e Pesquisa em Educação, jan.-abr., 1998.

LÉVY, Pierre. As tecnologias da inteligência: o futuro do pensamento na era da informática. Rio de janeiro: 34, 1994.

MACHADO, Nilson José. Conhecimento e Valor. São Paulo: Moderna, 2004.

MORAIS, M.C. O paradigma educacional emergente. São Paulo: Papirus, 2000.

MORAN, J.M. Mudanças na comunicação pessoal: gerenciamento integrado da comunicação pessoal, social e tecnológica. São Paulo: Paulinas, 1998. 
MUNHOZ, Siemsen Antonio. Tecnologias aplicadas à educação, educação e tecnologia na sociedade da informação. Curitiba: IBPEX, 2002.

PALAZZO, L.A.M. Modelos proativos para hipermídia adaptativa. Tese de Doutorado. PGCC da UFRGS, janeiro de 2000.

STERNBERG, Robert. Psicologia Cognitiva. Porto Alegre: ARTMED, $2000 .^{1}$ 